\title{
Velocity of auroral arcs drifting equatorward from the polar cap
}

\author{
P. J. S. Williams, C. F. del Pozo, I. Hiscock, R. Fallows \\ Adran Ffiseg, Prifysgol Cymru Aberystwyth, Ceredigion SY23 3BZ, Wales, UK e-mail: pjw@ aber.ac.uk
}

Received: 13 October 1997 / Revised: 30 April 1998 / Accepted: 3 May 1998

\begin{abstract}
The drift velocity of an auroral arc is compared with the component of F-region plasma velocity in the same direction for ten cases where the arc is seen to move steadily equatorward for several minutes without any major change in appearance or orientation. In most cases the two velocities are close, but on two occasions the drift velocity of the arc is much higher than the plasma velocity. From the cases studied it appears that during the growth and recovery phase of the substorm cycle the arc moves with a velocity close to the convection velocity, but during the expansion phase this is not the case.
\end{abstract}

Key words. Magnetospheric physics (auroral phenomena; electric fields; plasma convection)

\section{Introduction}

In recent years a number of papers (e.g. Haerendel et al., 1993; Lewis et al., 1994; Frey et al., 1996; Gazey et al., 1996) have discussed the relative movement of auroral features with respect to convecting flux tubes. This is important in understanding how energy from the magnetosphere is transferred to the auroral atmosphere, whether in the form of Joule heating by the Pedersen current or as an input of energetic particles.

At first it might seem a simple procedure to measure the apparent motion of an arc relative to the background convection. The drift of the arc can be monitored by optical measurements using an all-sky camera while the background convection is indicated by the F-region plasma velocity, as measured by a tristatic incoherent-scatter radar such as EISCAT. However, on closer examination it is obvious that neither of these

Correspondence to: P. J. S. Williams measurements is entirely straightforward, and the literature published on the subject does not provide a simple answer to the question of how auroral forms move with respect to the background convection.

In a 9-day campaign during February 1992 Frey et al. (1996) recorded auroral activity with an image-intensified CCD TV camera, while at the same time they used the EISCAT UHF radar to measure F-region plasma velocity. They reported six cases where the relative motion of the arc and the plasma was of the order of $200 \mathrm{~m} \mathrm{~s}^{-1}$, and in four of these the arc was moving more slowly than the plasma. In contrast Gazey et al. (1996) presented keograms of bright aurorae for a magnetically active period in February 1993 where in almost all cases the aurora appeared to move far more rapidly than the plasma; one auroral feature was observed moving equatorward at over $1 \mathrm{~km} \mathrm{~s}^{-1}$ while the plasma velocity in the same direction, as measured by EISCAT, was less than $300 \mathrm{~m} \mathrm{~s}^{-1}$. The authors concluded that during active substorm periods arc velocities measured in the nightside ionosphere can differ significantly from the convection velocity of the background plasma.

In contrast, Lewis et al. (1994) reported a case where a simple auroral arc was observed for $18 \mathrm{~min}$ as it drifted equatorward at a steady velocity close to the average plasma velocity in the same direction.

Both Frey et al. (1996) and Gazey et al. (1996) based their results on short campaigns where sensitive cameras were used to give a complete record of auroral activity with fine time resolution. In contrast, the optical observations analysed by Lewis et al. (1994), and those described in the present paper, were routine measurements made over a period of 9 years by the Finnish network of standard all-sky cameras. These optical measurements were of lower sensitivity than the TV records, and were made with much coarser time resolution (usually $1 \mathrm{~min}$ ). As a result this study is automatically restricted to those cases where a single auroral arc drifts steadily across the field of view for several minutes without any major change in appearance. These conditions impose stringent selection crite- 
ria on the examples chosen for analysis, and this undoubtedly affects the result obtained, as the rapidly moving and rapidly changing optical forms that are the usual signature of substorm onset are excluded. However, it is only when a simple auroral feature is moving steadily, without major change in appearance or orientation, that it is possible to define a single drift velocity; only in such cases can the optical and radar data be combined with confidence, and the combined data interpreted unambiguously.

\section{Observations}

The observations that form the basis of this paper are part of a general study of the electrodynamics of auroral arcs, carried out using data from the Finnish network of all-sky cameras, the EISCAT incoherent-scatter radar and the IMAGE magnetometer network, all located in the Nordic countries or on the Svalbard archipelago (see Table 1).

An optical arc, with a sharply defined lower boundary, is the clear signature of the precipitation of energetic electrons along a magnetic field line. An equivalent signature is provided by the sharp increase in electron concentration over the height range 100 $150 \mathrm{~km}$, as measured by the EISCAT UHF radar located near Tromsø. The plasma velocity $\mathbf{v}_{\mathrm{p}}$ at heights near $300 \mathrm{~km}$ (and the corresponding electric field $\mathbf{E}=-\mathbf{v}_{\mathrm{p}} \times \mathbf{B}$ ) can also be determined by EISCAT from the separate components of Doppler velocity measured at Tromsø and at two separate receiving stations at Kiruna and Sodankylä.

Because of the high electrical conductivity in an auroral arc associated with the enhanced E-region electron concentration, the electric field on a field line conjugate with an arc is always very low. However, in every case studied it appears that when a single, clearly defined auroral arc drifts steadily through the EISCAT beam it is also accompanied on one side (and one side only) by a parallel band of greatly enhanced electric field (Opgenoorth et al., 1990; Lewis et al., 1994; Lanchester et al., 1996). Such a peak in electric field strength is indicated by high plasma velocity, and the validity of this measurement can be confirmed by the associated Fregion ion frictional heating or E-region electron turbulent heating on the same magnetic field line, also measured by EISCAT (Williams et al., 1990).

This enhanced electric field is approximately perpendicular to the arc and always points in the same general direction as the background convection field. The parallel band where this field applies is offset from the arc in the opposite direction to the field itself. As a result the enhanced field drives a Pedersen current through a region of depleted conductivity into the arc, where current continuity is maintained by an upward fieldaligned current (FAC) (Opgenoorth et al., 1990; Lewis et al., 1994). It is important to remember this configuration when comparing the drift velocity of auroral arcs with the corresponding F-region plasma velocity.

\section{Measurement of the drift velocity of an auroral arc}

To measure the drift velocity of auroral arcs, optical records from the Finnish network of all-sky cameras, located at Hornsund, Kevo, Kilpisjärvi, Muonio or Sodankylä, were examined for the nine years 1987 to 1996. Care was taken to identify every case where a simple arc, aligned approximately east-west, was drifting
Table 1. Location of all-sky cameras, incoherent-scatter radar and magnetometers (ASC: all-sky camera, TR: transmitter and receiver, $\mathrm{R}$ : receiver, $\mathrm{E}$ : EISCAT magnetometer cross, I : IMAGE magnetometer network

\begin{tabular}{|c|c|c|c|c|}
\hline name & abbreviation & $\begin{array}{l}\text { geographic } \\
\text { latitude }\left({ }^{\circ} \mathrm{N}\right)\end{array}$ & $\begin{array}{l}\text { geographic } \\
\text { longitude }\left({ }^{\circ} \mathrm{E}\right)\end{array}$ & instrument \\
\hline \multicolumn{5}{|c|}{ all-sky-cameras } \\
\hline Hornsund & HOR & 77.00 & 15.60 & ASC \\
\hline Kevo & KEV & 69.76 & 27.01 & ASC \\
\hline Kilpisjärvi & KIL & 69.02 & 20.79 & $\mathrm{ASC}$ \\
\hline Muonio & MUO & 68.02 & 23.05 & $\mathrm{ASC}$ \\
\hline Sodankylä & SOD & 67.37 & 26.63 & ASC \\
\hline \multicolumn{5}{|c|}{ Incoherent scatter radar (EISCAT) } \\
\hline Tromsø & EIS-T & 69.58 & 19.22 & $\begin{array}{l}\text { TR (UHF) } \\
\text { TR (VHF) }\end{array}$ \\
\hline Kiruna & EIS-K & 67.86 & 20.44 & $\mathrm{R}(\mathrm{UHF})$ \\
\hline Sodankylä & EIS-S & 67.37 & 26.63 & $\mathrm{R}$ (UHF) \\
\hline \multicolumn{5}{|c|}{ Magnetometers (EISCAT X, IMAGE) } \\
\hline Sørøya & SOR & 70.54 & 22.22 & I \\
\hline Alta & ALT & 69.86 & 22.96 & $\mathrm{E}$ \\
\hline Kevo & $\mathrm{KEV}$ & 69.76 & 27.01 & $\mathrm{E} / \mathrm{I}$ \\
\hline Masi & MAS & 69.46 & 23.70 & I \\
\hline Kilpisjarvi & KIL & 69.02 & 20.79 & $\mathrm{E} / \mathrm{I}$ \\
\hline Kautokeino & KAU & 69.02 & 23.05 & E \\
\hline Muonio & MUO & 68.02 & 23.05 & $\mathrm{E} / \mathrm{I}$ \\
\hline Pello & PEL & 66.90 & 24.08 & $\mathrm{E} / \mathrm{I}$ \\
\hline Oulujärvi & OUJ & 64.52 & 27.23 & I \\
\hline Hankasalmi & HAN & 62.30 & 26.65 & I \\
\hline Nurmijävi & NUR & 60.50 & 24.65 & I \\
\hline
\end{tabular}


steadily equatorward while EISCAT was operating in a mode which provided continuous measurements of the F-region plasma velocity (e.g. the common programmes $\mathrm{CP} 1, \mathrm{CP} 2$, CP4 or CP5). The combination of a suitable auroral event in a clear, dark sky occurring at the same time as EISCAT was operating in a suitable mode was not very common, but ten cases have been selected for detailed study.

In this analysis the first task is to assign a single, accurate and unambiguous drift velocity to each arc. For this to be possible the arc must be simple in form and moving steadily in one direction without any major change in appearance or orientation. In reality arcs always show some curvature, and they change in appearance and orientation as the arc moves through the field of view. However, many quiet arcs are aligned approximately east-west, close to the McIlwain L-shells, and they move at a steady speed without major change of appearance: these can be considered as close approximations to the 'ideal' case.

In analysing the image of an arc in a single frame from the all-sky camera, the sharply defined lower boundary is identified and the azimuth and elevation of this boundary are measured at a series of points spaced along the arc. It is then assumed that this lower boundary is at a height of about $105 \mathrm{~km}$ (an assumption confirmed when the same arc is observed from more than one of the optical stations) and hence the geographic latitude and longitude of each point can be calculated.

The maximum distance of the arc from the all-sky camera is likely to be less than $200 \mathrm{~km}$ in every case, so it is a reasonable approximation to plot the whole boundary in quasi-rectilinear local co-ordinates. An appropriate sector of the arc is chosen and $\theta$, its orientation with respect to east-west, is determined by simple regression. This process is repeated for each successive image provided by the all-sky camera, and from the whole set of data the mean orientation of the arc, $\langle\theta\rangle$, can be determined, together with the standard deviation about this mean. Figure shows a typical example of this procedure; Fig. 1a illustrates an arc which was observed for over 10 min at Kilpisjärvi on 1 March 1995 as it moved equatorward. This example is close to the 'ideal' case as the orientation of the arc remains reasonably constant with an average value of $\langle\theta\rangle=4.8^{\circ}$ anti-clockwise from east-west and standard deviation of only $0.8^{\circ}$. Figure $1 \mathrm{~b}$ shows an arc which was observed at Kilpisjärvi for 6 min on 28 October 1992 in this case the orientation of the arc does change from minute to minute, with an average value of $14.0^{\circ}$ anti-clockwise from east-west and a standard deviation of $4.2^{\circ}$.

In the next stage of the analysis is given longitude is chosen, and for each frame the latitude at which the arc intersects the circle of longitude is measured. In a and $b$ of Fig. 2 these latitudes are plotted against time for the arcs observed on 1 March 1995 and on 28 October 1992, respectively. In each case regression analysis can be used to determine $\mathrm{d} \lambda / \mathrm{d} t$, the change of latitude per unit time at a particular longitude. The procedure is repeated at a
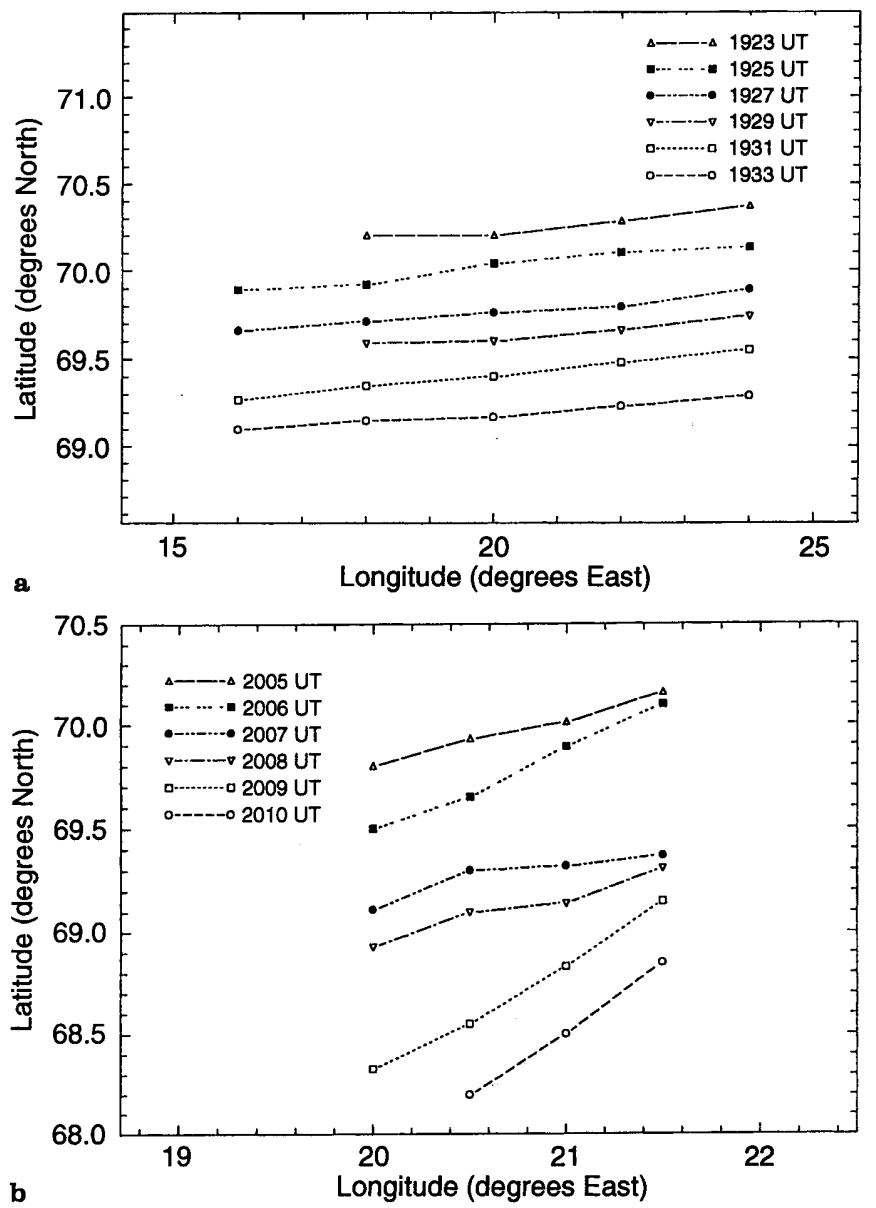

Fig. 1a,b. Alignment of auroral arc in latitude and longitude as observed at Kilpisjärvi $\left(69.0^{\circ} \mathrm{N} 20.9^{\circ} \mathrm{E}\right)$ a on 1 March 1995 between 1923 and 1933 UT. b on 28 October 1992 between 2005 and 2010 UT.

series of longitudes, all within the chosen arc sector, and for each arc the mean change of latitude per unit time over the whole sector $\langle\mathrm{d} \lambda / \mathrm{d} t\rangle$ is determined, together with the standard deviation. For example, if the position of the arc observed on 1 March 1995 is monitored over the longitude sector $16^{\circ} \mathrm{E}-24^{\circ} \mathrm{E}$ and the time-interval 1923 to 1933 UT then $\langle\mathrm{d} \lambda / \mathrm{d} t\rangle=-190 \mathrm{~m} \mathrm{~s}^{-1}$ with an uncertainty of only $5 \mathrm{~m} \mathrm{~s}^{-1}$. On the other hand, similar measurements for the arc observed on 28 October 1992 give an uncertainty of about $20 \mathrm{~m} \mathrm{~s}^{-1}$, and this is more typical.

Finally $\langle\mathrm{d} \lambda / \mathrm{d} t\rangle$ is multiplied by $\cos (\langle\theta\rangle)$ to give the best estimate of the drift velocity of the arc in a direction perpendicular to the arc itself. Note that this correction is not possible for estimates of drift velocity based on keograms alone, and such velocities are always overestimated. The final uncertainty quoted for the drift velocity of the arc, which is the combined uncertainty in $\langle\mathrm{d} \lambda / \mathrm{d} t\rangle$ and in $\cos (\langle\theta\rangle)$, is a single measure of the extent to which the arc in question moves steadily, without any major change in appearance or orientation. In other words this error gives an overall, objective indication of the extent to which it is possible to assign a single drift velocity to the arc in question. For the arc observed on 1 March 1995 it is $(190 \pm 10) \mathrm{m} \mathrm{s}^{-1}$ but for the arc 

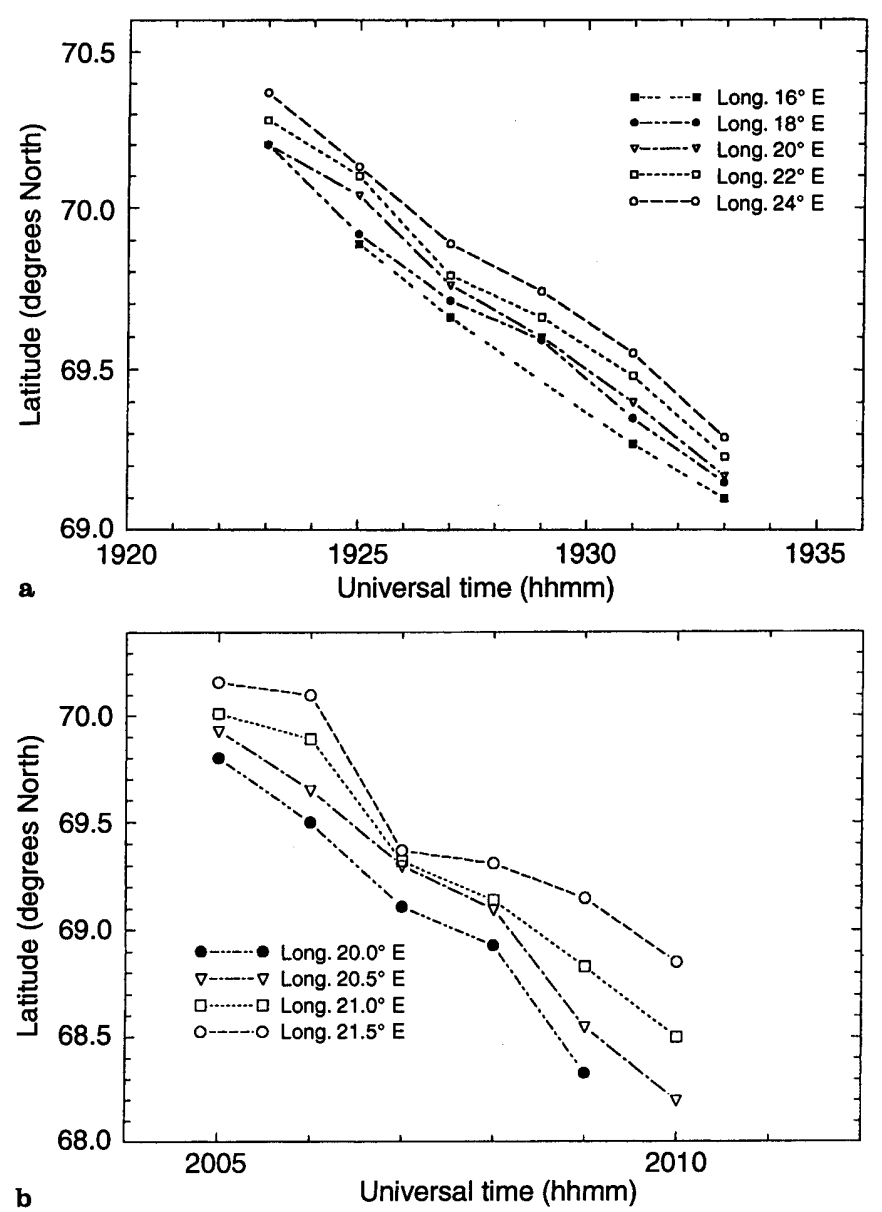

Fig. 2a,b Drift of an auroral arc in latitude along different circles of longitude as observed at Kilpisjärvi a on 1 March 1995 between 1923 and 1933 UT, b on 28 October 1992 between 2005 and 2010 UT

observed on 28 October 1992 it is $(470 \pm 50) \mathrm{m} \mathrm{s}^{-1}$, the larger error level reflecting the changes in appearance and orientation that this arc displayed.

\section{Measurement of convection velocity}

The measurement of convection velocity perpendicular to the arc is also subject to error and uncertainty. In five of the cases discussed in the present paper the EISCAT common programme $\mathrm{CP} 1$ was operating when the optical observations were being made. In CP1 the beam transmitted by the radar is held close to the local magnetic field line, so that the velocity vector is determined for a single volume of F-region plasma at a latitude of $69.1^{\circ} \mathrm{N}$, which 'maps' down the magnetic field line to an E-region latitude of $69.4^{\circ} \mathrm{N}$. The velocity measurement is achieved by combining the three components of Doppler velocity measured for that single volume at a single time by the EISCAT UHF receiving stations at Tromsø, Kiruna and Sodankylä. From the two components of plasma velocity perpendicular to the magnetic field line, $v_{\perp \mathrm{S}}$ and $v_{\perp \mathrm{W}}$, the plasma velocity in the direction perpendicular to the mean orientation of the arc can be calculated: $v=v_{\perp \mathrm{S}} \cos (\langle\theta\rangle)-v_{\perp \mathrm{W}} \sin (\langle\theta\rangle)$.

This mode has the advantage of providing unbiased estimates of the plasma drift velocity at a single point and is suitable for the study of auroral arcs which drift through the magnetic field line at Tromsø. However, CP1 measurements are made with a fixed beam and so they cannot on their own indicate any changes of drift velocity with latitude.

In three cases this problem was partly resolved by using EISCAT common programme CP2 where the radar followed a regular 6-min scanning pattern which included four separate pointing directions covering a latitude range $68.4^{\circ} \mathrm{N}$ to $69.6^{\circ} \mathrm{N}$. In one case $\mathrm{CP} 5$ was used, which combines a rapid and extensive north-south scan with more prolonged measurements along the Tromsø field line. On this occasion, these field-aligned measurements coincided with the passage of the arc overhead at Tromsø.

In the final case the arc was seen well to the north of Tromsø but fortunately the radar was operating CP4. In this mode the plasma velocity vector is estimated by using EISCAT in the 'beam-swinging' mode with the Tromsø antenna observing at low elevation towards the north, and alternating between two separate azimuth directions chosen so that the mean direction is approximately perpendicular to the McIlwain L-shell. This mode has the disadvantage that the beam swinging method inevitably introduces 'mixing' errors (Etemadi et al., 1989), but fortunately these errors are mainly in the component parallel to the L-shell and measurements perpendicular to the L-shell are reliable. The advantage of the CP4 mode is that it provides simultaneous measurements of plasma velocity over a wide range of latitudes.

These estimates of plasma velocity will normally be subject to substantial noise errors (Williams et al., 1996) as well as large minute-to-minute fluctuations (Williams et al., 1990, 1992; Lewis et al., 1992). A theoretical formula to estimate the uncertainty due to random noise in a measured component of velocity has been derived by Williams et al. (1996) and this has been confirmed to within $1 \%$ by comparison with the scatter in velocity measurements made simultaneously in CP4 at six different frequencies with the same pulse-scheme and the same signal-to-noise ratio. According to the formula, the standard error in the measurement of a single component of velocity at a wavelength $\lambda$ is given by

$$
\begin{aligned}
\delta v_{p}= & 0.17 \sqrt{\lambda}\left[1+\frac{2}{R}\right] \frac{\left(T_{i}\right)^{0.25}}{(\tau r t)^{0.5}}\left(1-0.16 \frac{T_{e}}{T_{i}}\right) \\
& \left(1+\frac{2.0 \cdot 10^{-4} \lambda}{\tau}\right) \sqrt{\left(1+\frac{1}{m\{1+R\}^{2}}\right)},
\end{aligned}
$$

where $\mathrm{R}$ is the signal-to-noise ratio over the bandwidth of the radar echo, $T_{i}$ and $T_{e}$ are the ion and electron temperatures, respectively, $\tau$ is the length of the pulse transmitted $r$ times per second, $t$ is the total integration time and $m$ is the number of background gates which are averaged and subtracted from the signal gate. 
The noise error in a single measurement based on $5 \mathrm{~min}$ of observation is typically about $50-60 \mathrm{~m} \mathrm{~s}^{-1}$ but the genuine variation in the plasma velocity from measurement to measurement is often even larger. In order to make a reasonable comparison with the drift velocity of the arc it is therefore recommended that the measured velocity vector is averaged over a period long enough to reduce the noise errors to an acceptable level but short enough for the average value to represent the convection during the period when the arc was observed. In practice a 30 -min average centred on the passage of the arc offers the best overall protection against large noise errors if the averaging period is too short and against large variations in the convection velocity itself if the period is too long.

In taking this average it is vital to exclude any measurements made on the field line passing through the arc itself, where the electric field and the associated plasma velocity are always very low owing to the high conductivity associated with the arc. It is almost as important to exclude measurements in the band of greatly enhanced electric field immediately adjacent to the arc, where a small error in $\langle\theta\rangle$ will convert part of the very large plasma velocity parallel to the arc into a spurious velocity component in the perpendicular direction. These precautions have not always been observed in previous attempts to measure the relative velocity of an arc with respect to the background convection.

In the case of the arc observed on 1 March 1995 the average plasma velocity measured by EISCAT in the direction perpendicular to the orientation of the arc, over the interval 1916-1946 UT, equals (160 \pm 20) $\mathrm{m} \mathrm{s}^{-1}$, very close to the estimated value of arc drift which equals $(190 \pm 10) \mathrm{m} \mathrm{s}^{-1}$. In contrast, the average plasma velocity perpendicular to the arc between 1945 and 2015 UT on 28 October 1992 which equalled $(240 \pm 30) \mathrm{m} \mathrm{s}^{-1}$, was much smaller than the drift velocity of the arc in the same direction, which equalled $(470 \pm 50) \mathrm{m} \mathrm{s}^{-1}$.

As the aim of the exercise is to compare two velocities which may be close in magnitude, unless all the precautions are heeded it is easy to obtain a spurious result. Even in the best examples there is a residual error in the relative velocity of at least $30 \mathrm{~m} \mathrm{~s}^{-1}$, and there is no way that it can be established without doubt that the relative velocity is less than this. However, with care the results in most cases are accurate enough to determine whether the relative velocity is less than $100 \mathrm{~m} \mathrm{~s}^{-1}$ or not.

\section{Results}

To illustrate how the relative velocity of the arc with respect to the background convection may depend on the phase of the substorm cycle, results are given in detail for four cases: one during the growth phase of a substorm, one during the expansion phase, one during recovery and one during a very quiet period when substorm activity, although observed, was very weak. In order to present a wide variety of cases without making the paper excessively long the examples presented have been deliberately chosen to be different from those already described in Lewis et al. (1994) and Williams et al. (1998) Further examples will be described in a future paper (del Pozo et al., in preparation).

\subsection{Growth phase}

At 1857 UT on 25 January 1993 an arc was observed near the northern horizon by the all-sky camera at Kilpisjärvi. It drifted equatorward at a steady speed, passing over the EISCAT site near Tromsø at 1902 UT, and it was last seen to the south at 1907 UT.

The broken line in Fig. 3a shows the average velocity of the arc as it drifted over EISCAT using the procedure described in Sect. 3 to derive a value of $(380 \pm$ 20) $\mathrm{m} \mathrm{s}^{-1}$.

The continuous line in Fig. 3a follows the successive values of plasma velocity perpendicular to the arc as measured by EISCAT between 1850 UT and 1920 UT during a run of the common programme $\mathrm{CP} 1$. The error bars for the plasma velocity are calculated using the equation from Williams et al. (1996) already quoted. On this occasion the convection velocity was fairly constant, and as none of the six values used to derive the average corresponded to measurements conjugate with the arc itself or with the band of enhanced electric field near the arc, a simple average provides the best estimate of plasma drift velocity equal to $(400 \pm 30) \mathrm{m} \mathrm{s}^{-1}$. In this case the agreement between the two values is about as good as the errors in arc drift velocity and in plasma velocity allow.

This event occurred on a moderately disturbed day when the X-component magnetograms from the IMAGE network, shown in Fig. 3b, suggest substorm onset at 1920 UT, so that the passage of the quiet arc occurred during the growth phase of the substorm cycle.

Very similar results for the substorm growth phase, with the drift velocity of the arc approximately equal to the average F-region plasma velocity, have been reported for 20 October 1987 (Lewis et al., 1994) and for 20 March 1990 (Williams et al., 1998).

In contrast, on 1 March 1995 an arc was observed south of EISCAT from 1827 to 1833 UT, preceding a sharp substorm onset at 1910 UT. The arc was almost stationary, with an estimated drift velocity of only $(30 \pm 30) \mathrm{m} \mathrm{s}^{-1}$, but the average plasma velocity measured by EISCAT had a southward component of $(170 \pm 20) \mathrm{m} \mathrm{s}^{-1}$. On this occasion, however, the arc remained south of EISCAT throughout the whole set of observations and as convection velocities tend to be smaller at lower latitude (e.g. del Pozo and Blanc, 1994) direct comparison of the two velocities must be qualified.

\subsection{Expansion phase}

On 28 October 1992 the arc described in Sect. 3 was first seen north of Kilpisjärvi at 2005 UT and it travelled very rapidly equatorward, passing over EISCAT at 2006 UT 

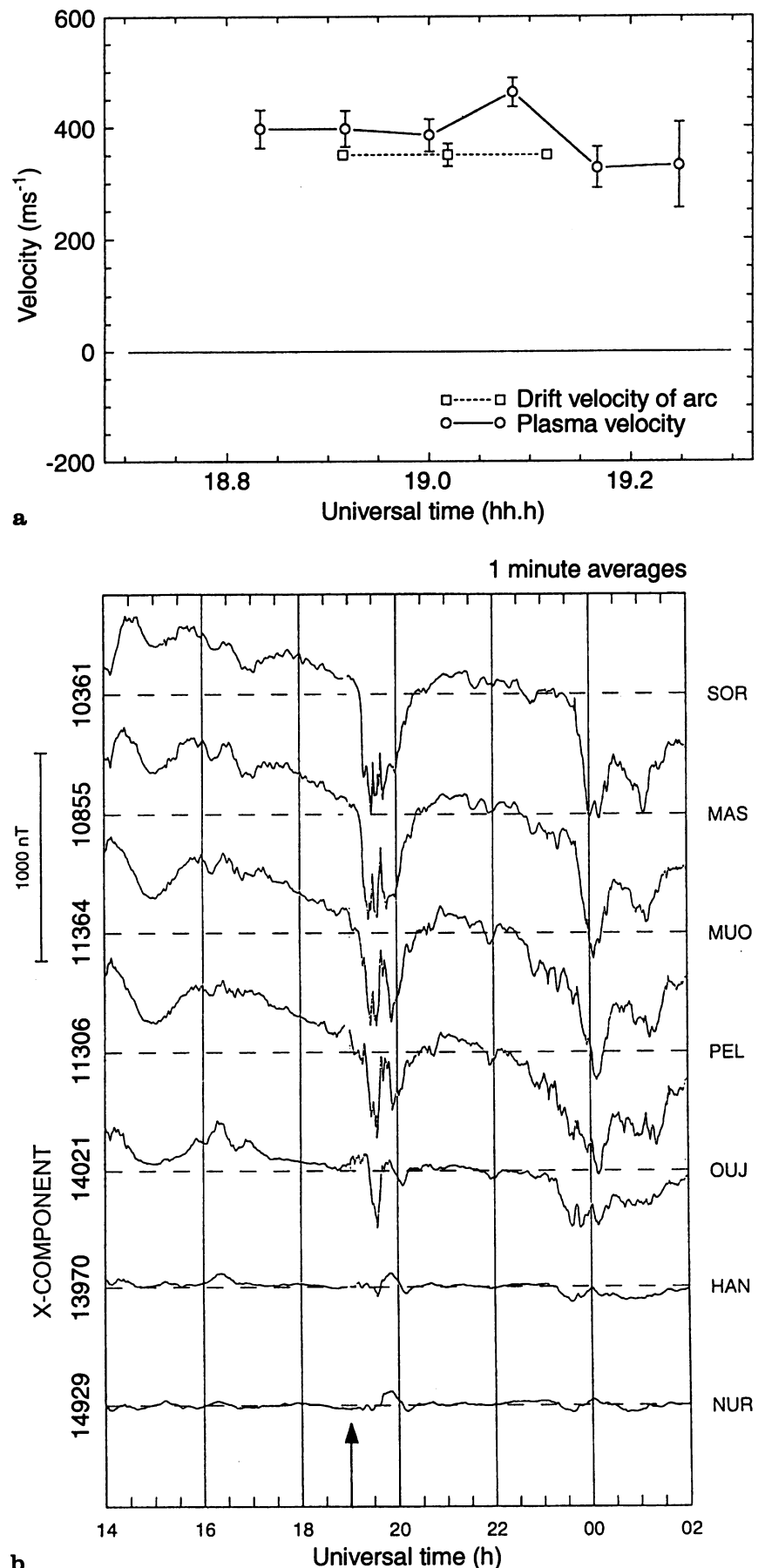

Fig. 3. a Comparison of arc drift velocity (indicated by broken line) and plasma velocity in the same direction (indicated by continuous line) for 25 January 1993. b X-component of magnetograms from the IMAGE network for 25-26 January 1993. The arrow indicates the time at which the arc was observed.

and reaching as far south as $68.4^{\circ}$ by 2010 UT. Following the procedure described in Sect. 3, the best estimate of the arc drift velocity, based on combined measurements at $20^{\circ}, 20.5^{\circ}, 21^{\circ}$ and $21.5^{\circ} \mathrm{E}$, is $(470 \pm 50) \mathrm{m} \mathrm{s}^{-1}$. The large error reflects the changing appearance and orientation of this auroral feature as it moved equatorward. Indeed, with an uncertainty of $\pm 50 \mathrm{~m} \mathrm{~s}^{-1}$ it was judged to be just inside the selection criteria described in the introduction ("a simple auroral feature moving steadily without major change in appearance").

Figure $4 \mathrm{a}$ allows a comparison between the drift velocity of the arc and the component of plasma velocity perpendicular to the arc between 1948 and 2018 UT. In this case each value of the plasma velocity represents the
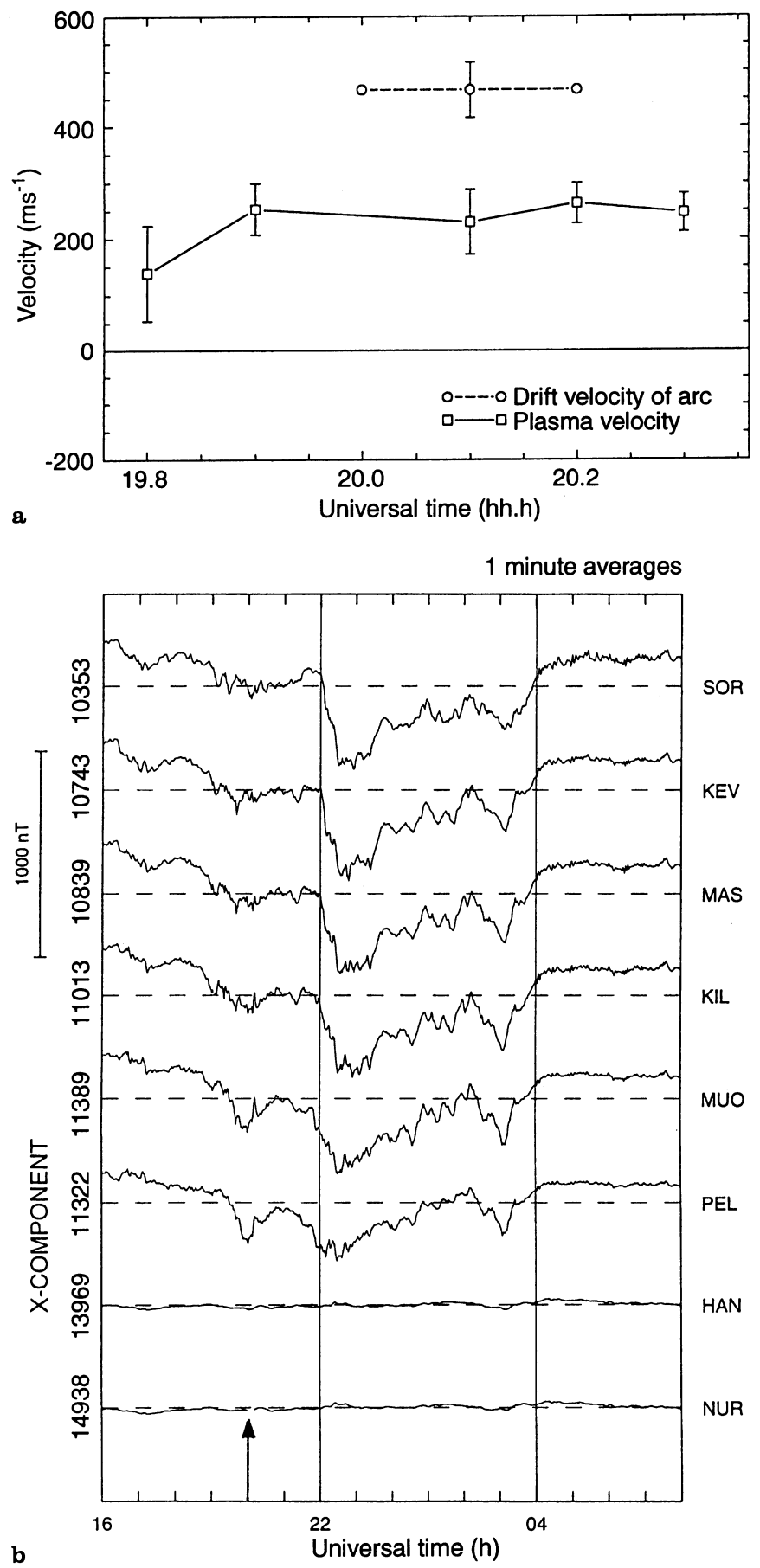

Fig. 4. a Comparison of arc drift velocity (indicated by broken line) and plasma velocity in the same direction (indicated by continuous line) for 28 October 1992. b X-component of magnetograms from the IMAGE network for 28-29 October 1992. The arrow indicates the time at which the arc was observed. 
average measured over a complete cycle of CP2 and the error bars in this case indicate the scatter of values from the different pointing directions covered in the cycle. The errors in both measurements are relatively large, but the arc is obviously moving at a speed significantly greater than the component of plasma velocity.

A possible explanation for this is provided by IMAGE magnetograms. Figure $4 \mathrm{~b}$ shows clearly that the passage of the arc overhead at EISCAT at 2005 UT coincided with the expansion phase of a substorm.

Similar results were recorded in 18 March 1988 during the expansion phase of a substorm. On that occasion the estimated drift velocity of the arc was greater than $600 \mathrm{~m} \mathrm{~s}^{-1}$ whereas the average plasma velocity in the same direction was $(70 \pm 20) \mathrm{m} \mathrm{s}^{-1}$ (Williams et al., 1998).

\subsection{Recovery phase}

The analysis of the data for 1 March 1995 has also been described in detail in Sect. 3. This was a disturbed day, and the auroral behaviour was complex with a series of arcs passing overhead. However, this particular arc drifted equatorward between 1923 and 1933 UT in a very regular manner, with an alignment held parallel to the local L-shell throughout. As already explained this behaviour allowed the drift velocity of the arc to be determined with high precision giving a value of $(190 \pm 10) \mathrm{m} \mathrm{s}^{-1}$.

In contrast, the component of plasma velocity perpendicular to the arc varied considerably, but the average value between 1916 and 1946 UT, (160 \pm 20) $\mathrm{m} \mathrm{s}^{-1}$, was close to the drift velocity of the arc, as shown in Fig. 5a.

When the IMAGE magnetograms are consulted (Fig. 5b), it appears that the arc was observed in the recovery phase of a sharply-defined substorm whose onset occurred at about 1910 UT, at a latitude centred close to EISCAT.

Very similar velocities were determined on another occasion during the recovery phase of a substorm. On 5 October 1989 there was a small substorm to the north of EISCAT with onset at 2310 UT, and an arc was monitored by the all-sky camera at Hornsund as it drifted from $78.3^{\circ} \mathrm{N}$ at $0048 \mathrm{UT}$ to $77.3^{\circ} \mathrm{N}$ at $0054 \mathrm{UT}$, with an average drift speed of $(180 \pm 50) \mathrm{m} \mathrm{s}^{-1}$.

On this occasion the plasma velocity was measured using the EISCAT Common Programme CP4, which uses 'beam-swinging' to determine the velocity of plasma flow over a range of latitudes towards the north. Although beam-swinging is an unreliable method of measuring the full velocity vector, it does give a reliable estimate of the component along the mean line-of-sight, which in this case lay almost perpendicular to the arc. Moreover, the noise errors for long-pulse monostatic measurements by the Tromsø UHF radar are smaller than for tristatic measurements because the scattering volume is much greater. However, on this occasion the measured convection velocity varied considerably with latitude and time and so the velocity data between 0040
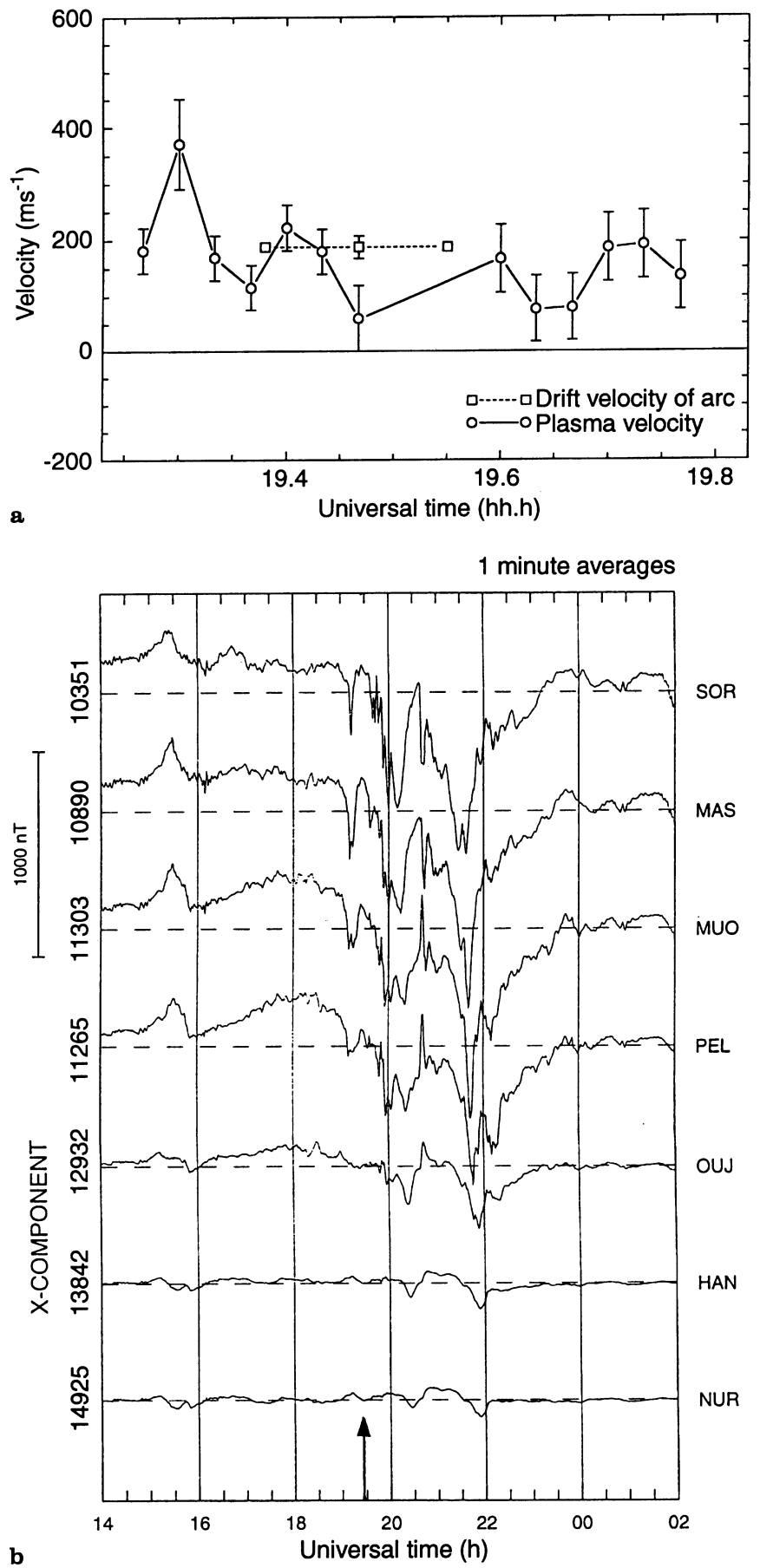

Fig. 5. a Comparison of arc drift velocity (indicated by broken line) and plasma velocity in the same direction (indicated by continuous line) for 1 March 1995. b X-component of magnetograms from the IMAGE network for 1-2 March 1995. The arrow indicates the time at which the arc was observed

and 0110 UT was averaged for gates 8 and 9. Although the final average $(140 \pm 60) \mathrm{m} \mathrm{s}^{-1}$ was reasonably close to the drift velocity of the arc, the large uncertainty in the average plasma velocity weakens the significance of the comparison. The full set of EISCAT velocity measurements for this example are included in Williams et al., (1998). 


\subsection{Quiet condition}

The final example occurred when geomagnetic conditions were very quiet but the IMAGE magnetograms show that the quiet arc which was observed by the allsky camera at Kilpisjärvi occurred during the recovery phase of a weak substorm. (Note that the scale of the magnetometer plot shown in Fig. $7 \mathrm{~b}$ is five times more sensitive than in the other IMAGE magnetograms included in this paper). The arc remained almost stationary between 0123 and 0134 UT, and when the normal procedure was applied the average equatorward velocity was only $(70 \pm 40) \mathrm{m} \mathrm{s}^{-1}$.

On this occasion EISCAT was running $\mathrm{CP} 5$, a programme which combined a rapid north-south scan with extra observing time along the Tromsø field line. By luck the scan included two measurements of plasma velocity spaced either side of the arc itself, marked $x$ and $y$ in Fig. 6, which confirm the quiet conditions that applied at this time. When the plasma velocity in the drift direction is averaged over the two positions the result is equal to $(90 \pm 30) \mathrm{m} \mathrm{s}^{-1}$.

\section{Conclusions}

A full interpretation of these results must set the movement of an auroral arc within the whole context of a global auroral substorm [see, for example, the review by Elphinstone et al. (1996)]. In particular, the flow of energy into an auroral arc must derive from wave and particle energy stored within flux-tubes in the magnetotail, and the relative movement of the arc with respect to the flux-tubes must be one of the factors controlling this energy flow and in future we must attempt to relate the total energy input with the phase of the substorm, the location of the arc and its motion with respect to the background convection. This is an

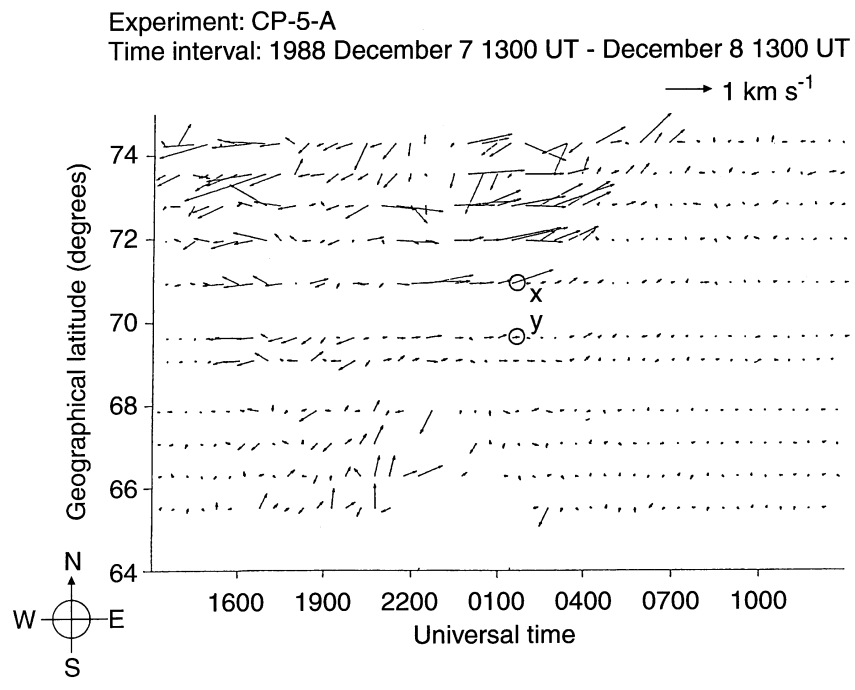

Fig. 6 EISCAT measurements of plasma velocity on 7-8 December 1988. The arc was observed between the locations represented by ' $\mathrm{x}$ ' and ' $y$ '
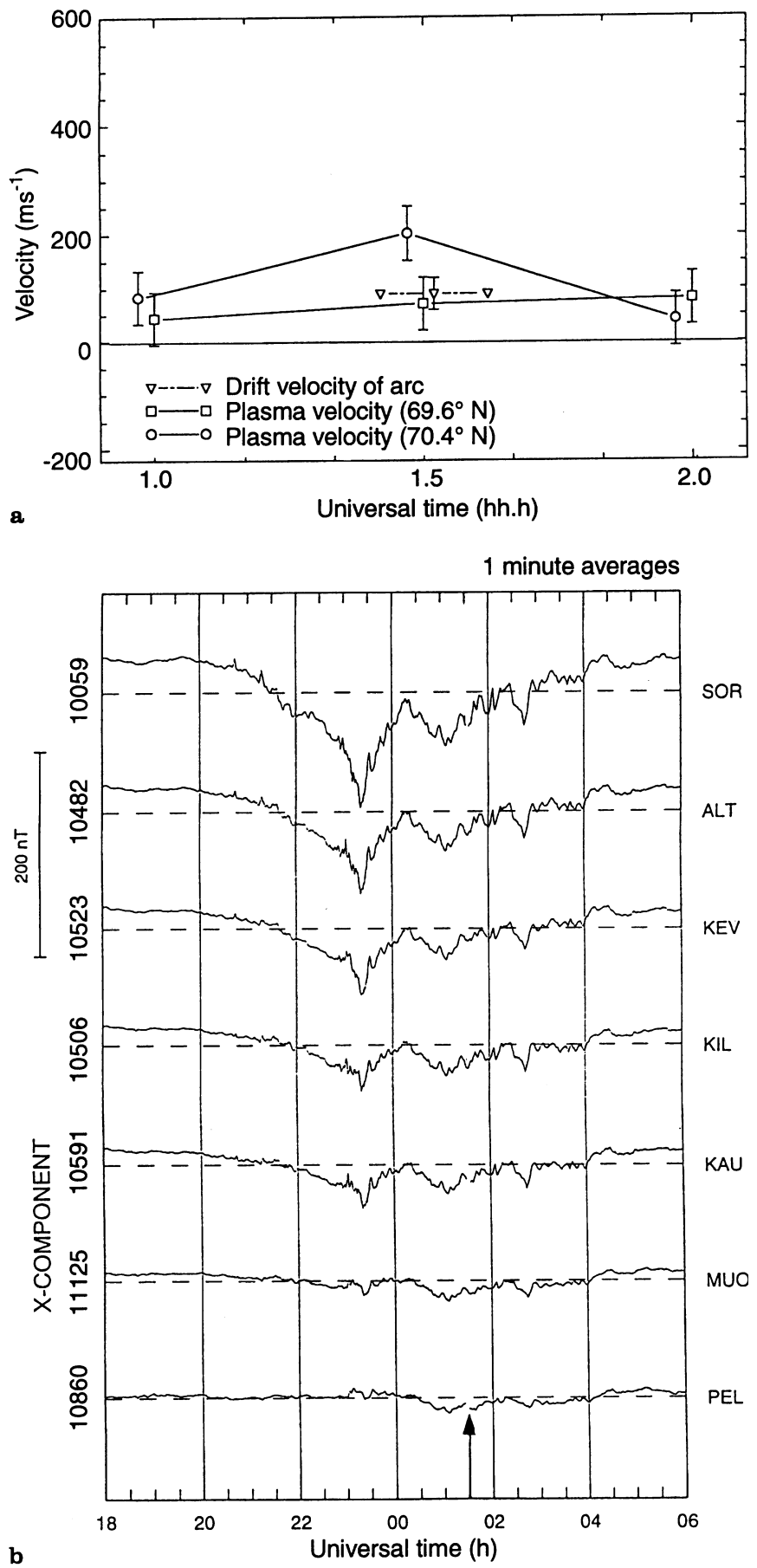

Fig. 7. a Comparison of arc drift velocity (indicated by broken line) and plasma velocity in the same direction at two latitudes (indicated by continuous lines) for 8 December 1988. b X-component of magnetograms from the IMAGE network for 7-8 December 1998. The arrow indicates the time at which the arc was observed

ambitious programme and this paper concentrates on the question of measuring the relative motion of an arc in the simplest possible cases.

The results from the ten cases considered are summarised in Table 2. In judging these results it must be repeated that there are many sources of uncertainty in measuring both the drift velocity of an auroral feature and the F-region plasma velocity due to convection. 
Table 2. Drift velocity of an auroral arc $(\perp$ arc $)$ compared with $\mathrm{F}$-region plasma velocity $(\perp$ arc) $(*$ arc does not cross EISCAT beam)

\begin{tabular}{|c|c|c|c|c|}
\hline $\begin{array}{l}\text { date }(\mathrm{y}-\mathrm{m}-\mathrm{d}) \\
\text { time (UT) }\end{array}$ & $\begin{array}{l}\text { latitude range over } \\
\text { which arc is observed }\end{array}$ & $\begin{array}{l}\text { drift velocity of } \\
\operatorname{arc}(\perp \operatorname{arc}) / \mathrm{m} \mathrm{s}^{-1}\end{array}$ & $\begin{array}{l}\text { plasma velocity } \\
(\perp \text { arc }) \mathrm{m} \mathrm{s}^{-1}\end{array}$ & $\begin{array}{l}\text { phase of } \\
\text { substorm }\end{array}$ \\
\hline $\begin{array}{l}1987-10-20 \\
2018-2028\end{array}$ & $69.1^{\circ}-71.3^{\circ}$ & $190 \pm 20$ & $\begin{array}{l}150 \pm 30 \\
(\mathrm{CP} 2)\end{array}$ & growth \\
\hline $\begin{array}{l}1900-03-20 \\
2039-2042\end{array}$ & $68.6^{\circ}-69.2^{\circ}$ & $290 \pm 30$ & $\begin{array}{l}230 \pm 20 \\
(\mathrm{CP} 2)\end{array}$ & growth \\
\hline $\begin{array}{l}1993-01-25 \\
1858-1907\end{array}$ & $67.8^{\circ}-70.3^{\circ}$ & $380 \pm 20$ & $\begin{array}{l}400 \pm 30 \\
(\mathrm{CP} 1)\end{array}$ & growth \\
\hline $\begin{array}{l}1995-03-01 \\
1827-1833\end{array}$ & $67.9^{\circ}-68.4^{\circ *}$ & $30 \pm 30$ & $\begin{array}{l}170 \pm 20 \\
(\mathrm{CP} 1)\end{array}$ & growth \\
\hline $\begin{array}{l}1988-03-18 \\
1845-1850\end{array}$ & $69.5^{\circ}-72.1^{\circ}$ & $680 \pm 40$ & $\begin{array}{l}70 \pm 20 \\
(\mathrm{CP} 1)\end{array}$ & expansion \\
\hline $\begin{array}{l}1992-10-28 \\
2005-2010\end{array}$ & $68.4^{\circ}-70.2^{\circ}$ & $470 \pm 50$ & $\begin{array}{l}240 \pm 30 \\
(\mathrm{CP} 2)\end{array}$ & expansion \\
\hline $\begin{array}{l}1988-12-08 \\
0123-134\end{array}$ & $70.7^{\circ}-71.2^{\circ}$ & $70 \pm 40$ & $\begin{array}{l}90 \pm 30 \\
(\mathrm{CP} 5)\end{array}$ & $\begin{array}{l}\text { recovery } \\
\text { (very quiet) }\end{array}$ \\
\hline $\begin{array}{l}1989-10-05 \\
0048-0054\end{array}$ & $77.3^{\circ}-78.3^{\circ}$ & $180 \pm 50$ & $\begin{array}{l}140 \pm 60 \\
(\mathrm{CP} 4)\end{array}$ & recovery \\
\hline $\begin{array}{l}1995-03-01 \\
1734-1737\end{array}$ & $70.0^{\circ}-70.2^{\circ} *$ & $70 \pm 20$ & $\begin{array}{l}120 \pm 50 \\
(\mathrm{CP} 1)\end{array}$ & recovery \\
\hline $\begin{array}{l}1995-03-01 \\
1923-1933\end{array}$ & $69.1^{\circ}-70.4^{\circ}$ & $190 \pm 10$ & $\begin{array}{l}160 \pm 20 \\
(\mathrm{CP} 1)\end{array}$ & recovery \\
\hline
\end{tabular}

Apart from some uncertainty in the height of the observed lower boundary, the basic source of error in estimating the drift velocity of an auroral arc is that the shape of the feature usually changes with time, and this often makes it impossible to define a single, accurate velocity that applies to the whole of the feature. Thus no examples of the poleward reversal often observed at substorm onset are covered by the selection criteria, although two examples of this will be discussed in a subsequent paper, using data from cameras with high time resolution (del Pozo et al. in preparation). There are cases, however, where a simple arc can be seen drifting across the sky for $5 \mathrm{~min}$ or more without showing any major change in shape or orientation and for these it is possible to quote a realistic value of drift velocity with a reasonable error.

It is even more difficult to make a confident measurement of the average convection velocity. The errors in measurements of plasma velocity due to system noise are often considerable, and the large and rapid variations in time and space add to the overall uncertainty. Moreover, in the vicinity of the arc itself the plasma velocity is strongly perturbed, being greatly reduced on field-lines conjugate with the arc yet greatly enhanced on neighbouring field lines.

To reduce the uncertainty in plasma velocity arising from system noise and the intrinsic variation with time there is no alternative to averaging the data over intervals as long as half an hour. It is more difficult to allow for the variations in space, especially when the auroral arc is drifting to lower L-shells where the convection velocity may be systematically smaller (e.g. del Pozo and Blanc, 1994). Low-elevation, beamswinging radar observations, such as the EISCAT common programme $\mathrm{CP} 4$, can help to resolve this problem, as can measurements by HF radars such as those in the SuperDARN network, including CUTLASS.
Bearing in mind the many difficulties in making an accurate comparison between the drift velocity of an arc and the background convection velocity we warn that any conclusions must be tempered by strong reservations. There are certainly many occasions when the drift velocity of an arc is close to the background convection velocity, though it is unlikely that the errors and uncertainties can ever be reduced to such an extent that it is possible to rule out a small relative velocity. With equal certainty there are many occasions when arc velocities differ significantly from the convection velocity.

In contrast to the suggestion by Gazey et al. (1996) that even during the growth phase of a substorm the arc velocity may be considerably larger than the background plasma velocity, the examples studied in the present paper suggest strongly that during the growth and recovery phases of a substorm it is likely that arc velocities will be close to the convection velocity. However, the two examples observed during substorm onset were undoubtedly travelling at velocities far higher than background convection.

The difference between arc drift during growth and during expansion is illustrated very clearly by keograms taken on 13-14 February 1996. In two separate cases a faint arc is seen drifting equatorward at a velocity close to the average convection velocity. At the moment of substorm onset, as indicated by magnetometer records, the arc brightens and immediately the arc begins to drift poleward whereas the plasma velocity does not change direction. An analysis of these two events, carried out with data from a range of different instruments, is the subject of a companion paper (del Pozo et al., in preparation).

Acknowledgements. We thank the director and staff of EISCAT for the quality and reliability of the common programme data used in this work. We also thank the Finnish Meterological Institute for providing the all-sky camera data and the data from the IMAGE 
magnetometers. Three of us (CdP, IH and RF) are indebted to the UK PPARC for support during the period when this work was carried out.

The Editor-in-chief thanks R. Lewis and another referee for their help in evaluating this paper.

\section{References}

del Pozo, C. F., and M. Blanc, Analytical self-consistent model of the large-scale convection electric field, J. Geophys. Res., 99, 4053-4068, 1994

Elphinstone, R. D., J. S. Murphee, and L. L. Cogger, What is a global auroral substorm? Rev. Geophys., 34, 169-232, 1996.

Etemadi, A., S. W. H. Cowley, and M. Lockwood, The effect of rapid changes in ionospheric flow on velocity vectors deduced from radar beam-swinging experiments, J. Atmos. Terr. Phys, 51, 125-138, 1989.

Frey, H. U., G. Haerendel, D. Knudsen, S. Buchert, and O. H. Bauer, Optical and radar observations of the motions of auroral arcs, J. Atmos. Terr. Phys., 58, 57-69, 1996.

Gazey, N. G. J., P. N. Smith, R. P. Rijnbeck, M. Buchan, and M. Lockwood, The motion of auroral arcs within convective plasma flows, Proc. 3rd International Conference on Substorms, ESA SP-389, pp 11-16, 1996.

Haerendel, G., S. Buchert, C. La Hoz, B. Raaf, and E. Rieger, On the proper motion of auroral arcs, J. Geophys. Res., 98, 69876099, 1993.
Lanchester, B. S., K. Kaila, and L. W. McCrea, Relationship between large horizontal electric fields and auroral arc elements, J. Geophys. Res., 101, 5075-5084, 1996.

Lewis, R. V., P. J. S. Williams, T. S. Virdi, T. K. Yeoman, and M. Lester, EISCAT measurements of bursts in plasma velocity during substorm activity, Proc. ESA Symphosium on Substorms, Kiruna, pp 125-129, 1992.

Lewis, R. V., P. J. S. Williams, G. O. L. Jones, H. Opgenoorth and M. A. L. Persson, The electrodynamics of a drifting auroral arc, Ann. Geophysicae, 12, 478-480, 1994.

Opgenoorth, H. J., I. Häggström, P. J. S. Williams, and G. O. L. Jones, Regions of strongly enhanced perpendicular electric fields adjacent to auroral arcs, J. Atmos. Terr. Phys., 52, 449458, 1990.

Williams, P. J. S., G. O. L. Jones, B. Jones, I. Häggström, and H. Opgenoorth, Rapid variations in the magnetospheric electric field, J. Atmos. Terr. Phys., 52, 439-448, 1990.

Williams, P. J. S., R. V. Lewis, T. S. Virdi, M. Lester, and E. Nielsen, Plasma flow bursts in the auroral electrojets, Ann. Geophysicae, 10, 835-848, 1992.

Williams, P. J. S., A. Etemadi, I. W. McCrea, and H. Todd, Errors due to random noise in velocity measurements using incoherent scatter radar, Ann. Geophysicae, 14, 1480-1486, 1996.

Williams, P. J. S., C. del Pozo, and I. Hiscock, Drift velocity of auroral arcs. Adv. Space Res., in press, 1998. 